\title{
A IMPORTÂNCIA DA MEMÓRIA EM ROMANCES DE LETICIA WIERZCHOWSKI
}

\author{
Gabriela Fonseca Tofanelo \\ Mestra em Estudos Literários pela UEM \\ gabriela.tofanelo@gmail.com
}

\section{RESUMO}

Este artigo tem por objetivo analisar a importância da memória no processo de escrita e de construção da identidade familiar da autora gaúcha, descendentes de poloneses, Leticia Wierzchowski. Tal tema se faz presente nas seguintes obras que serão, aqui, discutidas: Uma Ponte para Terebin (2006) e Os Getka (2010). Esses romances retratam, por meio de memórias e recordações, famílias polonesas que tiveram a difícil e dolorosa tarefa de emigrar de seu país de origem e viver em terra desconhecida. As narrativas funcionam como um importante documento histórico da formação cultural do Brasil. Como aporte teórico, esta pesquisa se embasará, principalmente, nos pressupostos acerca da memória estudados por Le Goff (2013), Huyssen (2000) e Seligman-Silva (2003).

Palavras-chave: Memória, Identidade, Leticia Wierzchowski.
This research aims to analyze the importance of memory in the writing process and the construction of the family identity of the Gaucho author, descendants of Poles, Leticia Wierzchowski. This theme is present in the following works that will be discussed here: Uma ponte para Terebin (2006) and Os Getka (2010). These novels portray, through memories, Polish families who had the difficult and painful task of emigrating from their country of origin and living in an unknown land. These narratives function as an important historical document of the cultural formation of Brazil. As a theoretical contribution, this research will be based mainly on the assumptions about memory studied by Le Goff (2013), Huyssen (2000) and Seligman-Silva (2003).

Keywords: Memory. Identity. Leticia Wierzchowski.

\section{ABSTRACT}

\section{PARA INICIAR}

A memória consiste na capacidade do ser humano de conservar certas informações por meio de um conjunto de funções psíquicas que permitem atualizar dados passadas, conceitua Jacques Le Goff, em História e Memória (2013). Afirma que, por isso, é objeto de 
estudo das mais diferentes áreas, a saber: psicologia, neurofisiologia, biologia e psiquiatria, para citar alguns exemplos.

Por meio da memória, o indivíduo consegue organizar suas lembranças, fazer uma releitura delas, ressignificar diversos aspectos de sua vida e, até mesmo, de fato, entender o seu passado e a sua história.

Para o autor, o estudo acerca da memória é essencial para a análise de questões de identidade, seja individual ou coletiva, cuja busca é uma das preocupações fundamentais das sociedades atuais. Nas palavras também de Pollak:

a memória é um elemento constituinte do sentimento de identidade, tanto individual como coletiva, na medida em que ela é também um fator extremamente importante do sentimento de continuidade e de coerência de uma pessoa ou de um grupo em sua reconstrução de si. (1992, p. 204)

Desta forma, o estudo deste termo é fundamental para se analisar algumas obras da escritora contemporânea Leticia Wierzchowski, autora gaúcha, descendente de poloneses e conhecida por ter escrito $A$ casa das sete mulheres (2002), obra adaptada para televisão e traduzida para diversos países. Escreveu, ainda, outros 15 romances, além de coletâneas de contos e obras de literatura infantil. Um fato chama atenção em alguns de seus romances: o interesse em retratar as memórias de seus antepassados poloneses, como uma forma de busca de sua própria identidade e também da sobrevivência da memória polonesa no âmbito familiar.

Esta pesquisa trata-se, portanto, de analisar os rastros da memória polonesa na época da Segunda Guerra Mundial na obra de Leticia Wierzchowski. Como corpus, serão percorridas duas obras: Uma Ponte Para Terebin, 2005, que revela a história do avô da autora, Jan Wierzchowski, que veio para o Brasil e aqui constituiu família; e Os Getka (2010), romance cujo narrador utiliza-se dos processos da memória para tentar entender sua vida, revelando traços muito parecidos com a história da família Wierzchowski. 
Para dar subsídio teórico, serão utilizados os pressupostos acerca da memória estudados por autores como Le Goff (2013), Seligman-Silva (2003), Huyssen (2000), entre outros.

\section{UMA PONTE PARA TEREBIN: A REALIDADE EM FORMA DE FICÇÃO}

É incontável o número de escritores que já abordaram as famosas guerras mundiais. Segundo Seligman-Silva (2003), este fenômeno trata da "necessidade premente de narrar a experiência vivida" (p.46). Pode-se dizer também da necessidade de compartilhar dores e sofrimentos, pois este tema, as Guerras Mundiais, está vinculado à coletividade e não ao sofrimento individual, conforme aponta Douek:

A história coletiva é a lembrança viva, passado ainda vivo que os grupos carregam, história vivida do qual o próprio indivíduo participou ou ouviu falar, relato ainda prenhe de sentido de testemunhas, depoimentos através do quais o passado continua a viver em nós, corrente contínua de pensamento e experiência (2003, p.28)

Uma Ponte para Terebin (2006) foi o oitavo romance escrito por Leticia Wierzchowski. Como já supracitado, a fábula deste romance consiste, basicamente, em percorrer a trajetória de Jan Wierzchowski, polonês que deixou sua terra natal para estabelecer vínculos e família no Brasil. A narração da história é homodiegética, feita pela própria neta do protagonista, desta forma, a própria autora é, também, personagem e narradora deste romance.

A pesquisadora Zilá Bernd (2014), ao abordar em suas pesquisas o romance memorial, afirma que este tipo de obra se articula por meio de vestígios familiares que a/o escritora/o precisará complementar com sua imaginação, rendendo uma espécie de homenagem aos seus antepassados, no caso do livro citado, o avô da autora.

Estes vestígios são parte fundamental para a recriação do passado do avô. Wierzchowski certamente empreendeu um longo processo de busca por esses vestígios, como afirma no livro: "Não haveremos de deixar mais do que isso. Rastros. Papéis 
amarelados que o tempo e o desleixo haverão de consumir. Fotografias que já perderam o brilho." (WIERZCHOWSKI, 2006, p. 102). Além, é claro, de extensa pesquisa histórica acerca da Segunda Guerra Mundial.

A narradora, neste trecho, aborda a questão dos rastros e vestígios, compostos de cartas na íntegra trocadas pelo avô e sua família durante a guerra, fotografias, além de testemunhos orais passados de geração para geração. Le Goff (2013) chama a atenção para a importância do surgimento da fotografia no século XX, pois elas conferem uma veracidade nunca antes atingida, revolucionando os estudos e as escritas sobre memórias, dando-lhes precisão e a possibilidade de guardá-las. O mesmo serve para as cartas.

É, portanto, por meio dessas lembranças que vamos, junto com a autora, descobrindo a trajetória de vida de Jan Wierzchowski. O fato de ter servido ao exército por muitos anos confere-lhe um alto sentimento patriótico, o qual ele passa para a sua neta, mesmo esta tendo nascido no Brasil. Entretanto, este fato não foi suficiente para impedir que ele deixasse Polônia, país que: "ele amou com incansável fervor até o último momento da sua vida" (WIEZCHOWSKI, 2006 p. 18), mas que vivia sob constante ameaça de invasões em seu território, já inteiramente partilhado e repartido entre várias nações por muito tempo. Acaba, portanto, vindo para o Brasil, para "a misteriosa e aterradora viagem que ele efetuaria com o intuito de mudar de vida" (WIERZCHOWSKI, 2006, p. 13).

Quando a guerra eclode, Jan se vê na obrigação patriota de voltar para a Polônia, por dois longos anos, para lutar por seu país e contra o nazismo. Novamente, o processo de deixar tudo para trás. Em um primeiro momento, foram os pais; agora é a esposa e os filhos que vão sofrer com a ausência de Jan.

Neste sentido, pode-se pensar no termo "Literatura de testemunho", um conceito que vem alterando a percepção de diversos teóricos entre a relação Literatura e Realidade. É o que aponta Márcio Seligmann-Silva, em História, memória, literatura: o testemunho na era das catástrofes (2003). O autor afirma que não só aquele que viveu um martírio pode testemunhar, para ele, a literatura já possui um alto teor testemunhal, o que justifica 
estudar este livro, escrito por uma pessoa que não viveu essa história, mas foi destinada à esta narração, ainda que por meio de testemunhos de outros.

Tendo nascido no Brasil na década de 1970, Leticia Wierzchowski não viveu a aflição da Segunda Guerra Mundial como muitos de seus antepassados, nem a inevitabilidade de ter que fugir do país. Porém, é como se ela possuísse uma memória herdada, da qual trata Pollak (1992). A memória da comunidade polonesa passa a ser, também, a memória de Leticia e esse vínculo manifesta-se nas muitas histórias narradas pela personagem.

Pode-se afirmar, assim, que Wierzchowski, ao narrar histórias de sua família e ao entrar em contato com a memória coletiva da mesma e de tantos outros poloneses que passaram por igual situação, está reconstruindo sua identidade e criando vínculos com o passado.

Outro ponto que salta aos olhos na narrativa são os relatos acerca da dificuldade de viver em terras estranhas, de não falar a língua local, de ver sua pátria sendo devastada por guerras e o sofrimento ao ficar longe. Com tudo isso, percebe-se o quanto é difícil o processo do ser imigrante. Por sorte, Jan casou-se com uma brasileira, filha de poloneses, que ia Ihe ensinando a língua e os costumes, conforme comprova o excerto:

ela era gente da sua gente, mas falava a língua que ali falavam e, por causa disso, uma boa parcela dos sofrimentos estava posta de lado - ela sabia ler os documentos, sabia pedir endereços, agradecer, barganhar e fechar um negócio, ela sabia o que dizer aos despachantes, à velha que vendia pão, ao homem da imobiliária... (WIERZCHOWSKI, 2006, p.66)

O tom do livro é melancólico, de luta e sobrevivência em local desconhecido, mas também de saudade e tristeza imensa do local de origem. Jan Wierzchowski ficou quase 30 anos sem ver o pai. Seu pai não conheceu os cinco netos que possuía, nem sua nora. Assim como deve ter sido, também, com as diversas famílias de diversas nacionalidades que neste país se instalaram, como japoneses, italianos, alemães, entre outros.

Uma Ponte para Terebin retrata a tristeza que é deixar o país em que se nasceu, o processo difícil e doloroso de deixar tudo para trás, de começar outra vida, e o quanto todo 
esse processo reflete nas identidades e formação de cada um. Identidade que as personagens tentam o tempo todo não esquecer. Mesmo vindo para o Brasil, a afirmação da identidade polonesa é recorrente. Verificável, por exemplo, durante a narrativa, no uso de termos em polonês, para os quais se tem um glossário ao final do livro. E ainda, na própria vida da autora, que faz questão de reviver um passado que não é seu, mas sente seu: "Então é disso que eu trato aqui, da memória das coisas vividas há tantos anos - da sua vida, Jan, e dos vestígios que dela me ficaram" (WIERZCHOWSKI, 2006).

\section{OS GETKA: O TRAUMA DA GUERRA}

Os discursos acerca da memória aumentaram consideravelmente a partir de 1980, impulsionados pelo debate acerca dos horrores do holocausto e da Segunda Guerra Mundial, conforme aponta Andreas Huyssen, em Seduzidos pela memória: arquitetura, monumentos, mídia (2010). Para o autor, esse tema é um lugar-comum universal da história traumática.

Em Os Getka (2010), Leticia Wierzchowski retrata mais uma vez uma família de poloneses que vieram para o Brasil fugindo da Segunda Guerra Mundial. Andrzej é o narrador da história. É um escritor que busca, tal qual Bentinho, de Machado de Assis, "atar as duas pontas da vida e restaurar na velhice a adolescência", Andrzej recorre à memória para tentar entender alguns acontecimentos de sua vida, agora que se encontra sozinho, como diz no trecho:

A única coisa que posso fazer, a única coisa que me permito fazer, é recordar (...) Na verdade, o passado de todos os homens parece uma espécie de mentira... Quem jamais poderá provar a veracidade daquilo que ficou para trás? Por isso, talvez, fazemos diários, tiramos fotografias, guardamos velhos impressos de teatro e gastas passagens de algum trem europeu onde um dia passamos uma tarde de nossas vidas. Imagens, borrões de tinta, peças de roupa, cartões postais apagados, recortes de jornal, mechas de cabelo e dentes de bocas que já não sorriem mais - tudo são provas, garantias de que um dia houve um passado, uma casa, uma tarde de sol, uma pessoa, um beijo. (WIERZCHOWSKI, 2010, p.10) 
O objetivo principal do narrador é refletir e entender a morte da sua amada e do amor não vivido pelos dois: "tão apaixonado que fui, jamais tive coragem de viver minha paixão" (WIERZCHOWSKI, 2010, p. 105).

Lylia Getka é filha de amigos dos pais do narrador. Ambas as famílias dividiam uma casa na praia, onde passavam todos os verões. Andrzej e Lylia cresceram juntos, descobriram juntos o primeiro amor, tinham certeza de que iriam viver um relacionamento duradouro. Mas isso não se concretiza. Este livro de memórias se inicia, justamente, quando o narrador descobre a morte de Lylia e lamenta tudo que não viveram, passando a lembrar do passado e os motivos que fizeram a vida dos dois seguirem caminhos diferentes: "quando ela morreu, eu senti o impacto de seu desaparecimento como uma dor" (WIERZCHOWSKI, 2010, p.120).

Em um primeiro momento, aparenta ser somente este o tema do livro, a simples história de um amor não vivido. Porém, ao percorrer suas memórias, revela o passado sofrível de sua família e, principalmente, da família Getka. Seu pai Jan, não por coincidência mesmo nome e mesma origem do avô da autora, também veio para o Brasil na época da Segunda Guerra Mundial, juntamente com Josef e Danya Getka, pais de Lylia.

$\mathrm{Na}$ ocasião em que encontra uma pasta com lembranças do pai sobre guerra, o narrador percebe que se trata de "uma elaborada documentação que o velho organizara para não se esquecer" (WIERZCHOWSKI, 2010, p.72). Andrzej, mesmo sabendo que estava errado, vasculha a pasta, escondido dos pais. Este momento ilustra um dos primeiros em que ele realmente entendeu o que significava o passado para a sua família:

Saber dessa pasta pesou-me na alma durante muito tempo. Tive pesadelos, perdi a fome e Halina cogitou que eu estivesse doente (...). Tudo se explicava, Jan estivera na guerra, ele vira aquelas coisas. (WIERZCHOWSKI, 2010, p.72-73).

Essa reconstrução é feita a partir das memórias de um menino, que ouvia histórias dos adultos quando criança, passando a compreendê-las, de fato, somente agora, recordando-as. Desse modo, tem-se uma narrativa a partir de muitas incertezas, como mostra o excerto abaixo: 
Sobre aqueles tempos difíceis, os adultos sempre falavam em voz baixa e em polonês, longe das crianças, geralmente tarde da noite, como se tudo tivesse sido parte de um mesmo pesadelo que todos tivessem sonhado juntos. (...) Havia muitas dúvidas sobre as quais não podia perguntar nada. Essas lacunas, eu preenchia com a imaginação (...) Luta armada, holocausto, campo de concentração. Eram palavras que eu esmerilhava havia anos, sem muita clareza, nem bons resultados (WIERZCHOWSKI, 2010, p. 50-51)

Assim, o passado vai se revelando aos poucos em meio às memórias sentimentais do narrador apaixonado. Passado este que se revela traumático para a família Getka. Desta forma, faz-se necessário a abordagem acerca do conceito de trauma.

Segundo Seligman-Silva (2003), em História, Memória, literatura: o testemunho na era das Catástrofes, trauma é um choque violento e um desencontro com o real, uma reescritura dolorosa do real. Para ser identificado como trauma, deve haver uma repetição constante e alucinatória da lembrança. Nestas situações, o passado é revivido de forma dolorosa, por meio de eventos específicos.

O trauma gerado pela segunda guerra mundial lançou pelos ares qualquer experiência da realidade e os padrões da normalidade. Para sobreviver, cada sobrevivente teve que se reinventar (DOUEK, 2003).

É o que acontece com Danya Getka, mãe da já citada personagem Lylia, quando revela: "o mesmo sonho, todas as noites, Annia... Há 25 anos que eu ouço o barulho daquele trem nos meus ouvidos. Nunca mais vi minha irmã." (WIERZCHOWSKI, p.62, 2010).

A personagem em questão revive em sua memória todas as noites, uma cena traumática dos campos de concentração nazistas. Ela conseguiu sobreviver, sua irmã não. Trata-se de uma memória involuntária, definida por Jacy Alves de Seixas (2004), como espontânea, feita de imagens que aparecem e desaparecem independentemente de nossa vontade, revelando-se por "lampejos bruscos". 
Sobre esta personagem, o narrador diz que há "alguma coisa nos seus olhos, nos seus ossos finos, no perfil do seu rosto delicado, fazia a gente estar sempre temendo por ela, como se corresse um perigo (WIERZCHOWSKI, 2010, p.43).

Este episódio traumático de seu passado acabou levando à personagem a um fim trágico, o suicídio: "pendurou-se ali, revirando os olhos para todos os pesadelos que a tinham perseguido durante a vida" (WIERZCHOWSKI, 2010, p.136). Danya Getka não suportou todos esses anos vivendo e revivendo este mesmo pesadelo, não sendo possível conseguir o esquecimento e distanciamento do episódio traumático.

Outra característica de narrativas de memória presente neste romance é a questão de marcas e cicatrizes, pois estas individualizam o sujeito. Segundo Luciana Hartmann (2011), trata-se da memória na pele, é como se as cicatrizes potencializassem a memória, conferissem verossimilhança e testemunho daquele fato.

A experiência do narrador, ainda menino, ao ver as marcas dos campos de concentração e da guerra deixadas no corpo de seus parentes, resultou em algo impactante, relembrado durante toda a narrativa, como mostra os seguintes excertos: "Número tatuado no antebraço" (p.43); "Aqueles números de um azul borrado. Meu rosto incendiou-se de uma vergonha sem explicação. Aqueles números eram uma espécie de nudez (p. 52); “Jan tinha lutado na guerra e tinha aquela cicatriz" (p. 17).

Nos dois primeiros trechos, trata-se de uma tatuagem com número que consta no braço de Danya Getka. No último trecho, o narrador revela que o pai também possui uma cicatriz de guerra. Esses trechos parecem ter o papel de instaurar a verdade para a história que ele está empenhado em narrar, como se fosse preciso ter informações deste tipo para o/a leitor/a crer nos horrores que a Segunda Guerra Mundial causou.

A importância da memória nesses romances está, portanto, na possibilidade de relembrar e, com isso, entender o passado e a construção de sua(s) identidade(s). Os vestígios familiares, os relatos, as cartas e as fotografias são elementos fundamentais nesse processo de reconstrução memorialística, que contribuíram para se pensar nos tempos de guerra e na condição do imigrante nas obras ficcionais de Leticia Wierzchowski. 


\section{CONSIDERAÇÕES FINAIS}

Para finalizar, é necessário ressaltar que, ao engendrar tais narrativas, Leticia Wierzchowski teve importantes e diversas contribuições: além de resgatar um importante passado para a sua família e para as próximas gerações da mesma, contribui para um importante registro histórico da, por vezes, esquecida participação dos poloneses na constituição da identidade brasileira e, neste caso, especificamente, do Rio Grande do Sul. E é importante ao mostrar, ainda, diversos processos transculturais que são gerados dessas imigrações e diásporas, ou seja, a "mistura de culturas", em que uma soma-se a outra, em vez de se excluir, processo vivido de forma intensa e constante no Brasil, com suas diversas e importantes nações que formaram-no culturalmente.

Embora não tenha sido o foco desta pesquisa, é importante salientar que a obra de Letícia Wierzchowski pode ser considerada uma das poucas que se tem conhecimento dessa tentativa de empreender a representação literária do percurso da imigração polonesa para o Brasil, o que demonstra que os estudos acerca destes dois romances não se esgotam somente no tema da memória. São romances riquíssimos em representações e discussões contemporâneas.

\section{REFERÊNCIAS}

BERND, Zilá. Romance memorial (ou familiar) e memória cultural: a necessidade de transmitir em um defeito de cor de Ana Maria Gonçalves. Organon. V. 29, no 57. Porto Alegre, RS: Editora do Instituto de Letras da UFRGS, 2014

DOUEK, Sybil Safdie. Memória e exílio. São Paulo: Escuta, 2003.

HARTMANN, Luciana. Gesto, palavra e memória: performances narrativas de contadores de causos. Florianópolis: Ed. da UFSC, 2011.

HUYSSEN, Andreas. Seduzidos pela memória: arquitetura, monumentos, mídia. Rio de Janeiro: Aeroplano, 2000. 
LE GOFF, Jacques. História e memória. Trad: Bernardo Leão. 7ạ edição revista - Campinas, SP: Editora da Unicamp, 2013.

POLLAK, Michael. Memória e identidade social. Estudos Históricos, Rio de Janeiro, v. 5, n. 10,1992

RICOEUR, Paul. A memória, a história, o esquecimento. Tradução Alain François [et al.]. Campinas: Editora da Unicamp, 2007.

SEIXAS, Jacy Alves. Percurso de memórias em terras de história: problemáticas atuais. In: BREXIAN, Stella, NAXARA, Márcia (org). Memória e (res)sentimento: indagações sobre uma questão sensível. 2ªed. - Campinas, SP: Editora da Unicamp, 2004

Seligman-Silva, Márcio. História, memória, literatura: o testemunho na Era das catástrofes. Campinas - SP: Editora da Unicamp, 2003

WIERZCHOWSKI, Leticia. Uma ponte para Terebin. Rio de Janeiro: Record,2006.

WIERZCHOWSKI, Letícia. Os Getka. São Paulo: Record, 2010

Artigo recebido em: 03 de abril de 2018. Artigo aprovado em: 29 de agosto de 2018. 